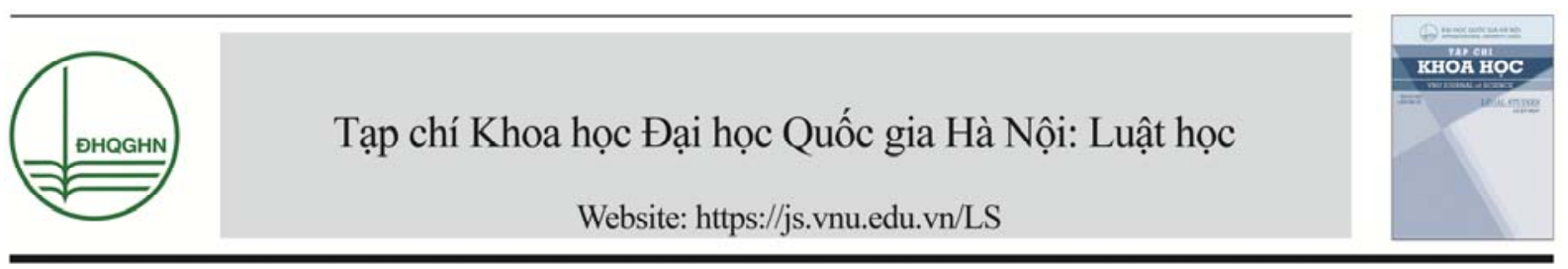

\title{
Luật Quốc tế và vai trò của các thiết chế phi nhà nước
}

\author{
Nguyễn Thị Thanh Hải* \\ Viện Quyền con nguời, Học viện Chính trị Quốc gia Hồ Chí Minh \\ 135 Nguyễn Phong Sắc, Cầu Giấy, Hà Nội \\ Ngày nhận 28 tháng 8 năm 2018 \\ Chỉnh sửa ngày 15 tháng 9 năm 2018; Chấp nhận đăng ngày 28 tháng 9 năm 2018
}

\begin{abstract}
Tóm tắt: Bài viết này tìm hiểu quá trình phát triển và những thay đổi về phạm vi điều chỉnh và chủ thể của luật quốc tế do tác động của quá trình toàn cầu hóa và những biến động trong đời sống chính trị, kinh tế và trật tự pháp lí quốc tế trong những thập kỷ gần đây. Thông qua việc phân tích vai trò của các thiết chế như tổ chức quốc tế, tổ chức phi chính phủ, các tập đoàn doanh nghiệp và cả vai trò của các cá nhân, bài viết khẳng định, ngày nay, quốc gia - mặc dù vẫn đóng vai trò quan trọng - nhưng không còn là chủ thể duy nhất. Pháp luật quốc tế chịu sự điều chỉnh của cả các thiết chế phi nhà nước.
\end{abstract}

Tư khóa: Pháp luật quốc tế, chủ thể, các thiết chế phi nhà nước.

Luật quốc tế là hệ thống các nguyên tắc và quy phạm pháp luật, được các quốc gia và chủ thể khác của luật quốc tế thỏa thuận xây dựng nên, trên nguyên tắc tự nguyện và bình đẳng, nhằm điều chỉnh những quan hệ phát sinh giữa quốc gia và các chủ thể đó trong mọi lĩnh vực của đời sống quốc tế. Kể từ khi ra đời, luật quốc tế thực hiện chức năng chủ đạo của mình là điều chỉnh mối quan hệ giữa các quốc gia với nhau. Trong vài thế kỉ gần đây, cùng với những biến đổi to lớn của đời sống chính trị, kinh tế và trật tự pháp lí toàn cầu, hệ thống pháp luật quốc tế đã có những bước mở rộng và phát triển đáng kể cả về đối tượng, chủ thể, nguồn và thẩm quyền pháp lí. Pháp luật quốc tế đã có sự dịch

\footnotetext{
* ĐT.: 84-989131688.

Email: thanhhai72@gmail.com

https://doi.org/10.25073/2588-1167/vnuls.4146
}

chuyển từ quan niệm truyền thống cho rằng ngành luật này chỉ bao gồm các nguyên tắc, chế định điều chỉnh mối quan hệ giữa các quốc gia sang một hệ thống pháp lí toàn cầu đa dạng hơn với sự tham gia của nhiều chủ thể khác nhau. Theo đó, luật quốc tế bao gồm cả những "quy định pháp luật về vai trò của các tổ chức, thiết chế quốc tế, điều chỉnh mối quan hệ giữa các tổ chức này với nhau cũng như mối quan hệ giữa các thiết chế này với quốc gia và cá nhân. Pháp luật quốc tế cũng đưa ra các quy định pháp lí về mối quan hệ của cá nhân và các chủ thể phi nhà nước khi quyền và trách nhiệm của cá nhân và các chủ thể phi nhà nước đó trở thành mối quan tâm của cộng đồng quốc tế" [1, tr.7]. Bài viết này tìm hiểu về quá trình chuyển đổi này cũng như vai trò của các chủ thể mới trong hệ thống pháp luật quốc tế hiện nay. 


\section{Quá trình mở rộng đối tượng và chủ thể tham gia của pháp luật quốc tế}

Vai trò và vị trí của các chủ thể phi nhà nước là một chủ đề thu hút được nhiều sự quan tâm về mặt học thuật. Các học thuyết pháp lí về vị trí của chủ thể phi nhà nước trong luật quốc tế đã làm thay đồi diện mạo của luật quốc tế hiện đại. Theo quan điểm của chủ nghĩa thực định thì luật quốc tế về thực chất không phải là luật vì trên thực tế không thể tồn tại một chính phủ chung toàn cầu để thực thi các quy định của pháp luật quốc tế. Quan điểm này trong thực tế không còn phù hợp bởi lẽ, ngày nay hệ thống pháp luật quốc tế cũng có những thẩm quyền pháp lí nhất định bao gồm thẩm quyền truy tố một số tội phạm quốc tế theo quy định của Tòa án hình sự quốc tế hay thẩm quyền xem xét giám sát việc thực hiện các điều ước quốc tế và tiếp nhận các khiếu kiện cá nhân theo hệ thống các cơ quan điều ước quốc tế về nhân quyền của Liên Hợp quốc. Sự phát triển của pháp luật quốc tế cũng được ghi nhận ở quá trình mở rộng phạm vi, lĩnh vực điều chỉnh từ việc chỉ giới hạn ở lĩnh vực ngoại giao, chủ quyền và toàn vẹn lãnh thổ đến những vấn đề toàn cầu mới xuất hiện như môi trường, $\mathrm{y}$ tế công, lao động, thương mại quốc tế và nhân quyền. Kết quả của quá trình mở rộng này là sự ghi nhận hàng ngàn các chuẩn mực quốc tế dưới nhiều hình thức khác nhau [2].

Nguồn của luật quốc tế cũng ngày càng được mở rộng thêm. Cùng với 5 nguồn cơ bản như quy định tại điều 38 (1) của Quy chế về Tòa án công lí quốc tế là điều ước quốc tế, luật tập quán quốc tế, các nguyên tắc chung của pháp luật quốc tế, quyết định tư pháp, các ấn phẩm đã được xuất bản [3], các quy định không có tính ràng buộc pháp lí (luật mềm) ngày một phát triển $[4, \operatorname{tr} .26]$. Mặc dù các quy định này không phải là nguồn chính thức của luật quốc tế và không được coi là văn bản pháp luật như cách tiếp cận của pháp luật thực định nhưng các văn bản luật mềm như nghị quyết, tuyên ngôn, khuyến nghị, hướng dẫn, quy tắc hành nghề do nhà nước và các chủ thể phi nhà nước khác xây dựng đóng vai trò quan trọng trong trật tự pháp lí quốc tế. Ngoài ra, các văn bản luật mềm không chỉ góp phần hình thành các quy phạm, chuẩn mực về những vấn đề toàn cầu mới xuất hiện mà còn là điểm khởi đầu quan trọng cho quá trình xây dựng hệ thống điều ước hay tập quán quốc tế. Trong nhiều trường hợp, luật mềm chính là công cụ để giải thích, làm rõ thêm các nội dung của một văn kiện pháp lí cụ thể $[5$, tr.1-75]. Chẳng hạn, Tuyên ngôn về Quyền của người khuyết tật do Đại hội đồng Liên Hợp quốc thông qua năm 1975 chính là sự chuẩn bị cho sự ra đời của Công ước quốc tế về Quyền của người khuyết tật được thông qua vào năm 2007. Tất cả các cơ quan điều ước của Liên Hợp quốc đều đã thông qua nhiều bình luận chung hay khuyến nghị về một số vấn đề cụ thể nhằm giải thích thêm các điều khoản được quy định trong từng công ước.

Có thể nói, bước phát triển quan trọng nhất của luật quốc tế hiện đại chính là quá trình chuyển đồi từ chỗ chỉ coi nhà nước là chủ thể duy nhất sang việc ghi nhận sự tham gia của nhiều chủ thể và thiết chế khác nhau vào quá trình điều chỉnh các mối quan hệ pháp lí quốc tế. Do tác động của quá trình toàn cầu hóa và tư nhân hóa, các chủ thể phi nhà nước ngày càng có nhiều mối quan hệ tương tác hơn với chính nhà nước trong toàn bộ quá trình xây dựng chuẩn mực, giám sát và thực thi pháp luật quốc tế bao gồm cả đàm phán và pháp điển hóa pháp luật, xây dựng hệ thống các văn kiện luật mềm, vận động chính phủ kí kết, phê chuẩn và thực hiện điều ước quốc tế. Kết quả của quá trình chuyển đổi này là bên cạnh vai trò của nhà nước thì các nhân tố phi nhà nước như tổ chức quốc tế, khu vực, tổ chức phi chính phủ, các doanh nghiệp và thậm chí cả các cá nhân ngày càng tham gia nhiều hơn vào hệ thống pháp luật quốc tế như là những chủ thể mới.

\section{Luật quốc tế và vai trò của các tổ chức quốc tế}

Các tổ chức quốc tế (đặc biệt là các tổ chức quốc tế liên chính phủ) là những chủ thể đóng vai trò quan trọng trong nền chính trị quốc tế 
thông qua việc tham gia vào hoạt động hoà giải, giải quyết xung đột, gìn giữ hoà bình, an ninh quốc tế cũng như quá trình thiết lập trật tự pháp lí. Thực tiễn pháp lí quốc tế trong thời gian qua đã ghi nhận nhiều đóng tích cực của các tổ chức quốc tế vào quá trình điều phối, quản trị các vấn đề toàn cầu. Nói cách khác, các tổ chức quốc tế đã đóng vai trò như là một phương tiện, một diễn đàn và là chủ thể tích cực giúp các quốc gia giải quyết những vấn đề mà các quốc gia không thể tự mình giải quyết [6, tr.33-35].

Với nghĩa là một công cụ, nhiều quốc gia thành viên coi tổ chức quốc tế là địa chỉ để thực hiện các mục tiêu của mình trong quá trình giải quyết xung đột, tạo lập hoà bình, thậm chí để gây ảnh hưởng đến quốc gia khác. Với nghĩa là một diễn đàn chung, các tổ chức quốc tế là nơi diễn ra hội nghị, đối thoại để các quốc gia cùng thảo luận về những chủ đề quan tâm chung. Nhiều tổ chức quốc tế như Liên Hợp quốc, Hội chữ thập đỏ và trăng lưỡi liềm đỏ quốc tế, WTO đã rất thành công trong việc tổ chức các diễn đàn này. Ngoài ra, tổ chức quốc tế cũng là một chủ thể tích cực tham gia vào quá trình trợ giúp, cải thiện đời sống cho mỗi cá nhân. Các tổ chức quốc tế hoạt động trong lĩnh vực nhân đạo là một ví dụ.

Đặt biệt, tổ chức quốc tế là những chủ thể trực tiếp tham gia vào quá trình xây dựng, thực hiện pháp luật quốc tế bao gồm cả việc đàm phán, kí kết, thông qua hay sửa đổi, bổ sung điều ước quốc tế. Các tổ chức này là nơi kết nối, phối hợp với các quốc gia trong quá trình xây dựng, thông qua điều ước quốc tế, đồng thời yêu cầu quốc gia thực hiện tốt nghĩa vụ của mình đối với pháp luật quốc tế. Kể cả khi các điều ước đã có hiệu lực thực thi, tổ chức quốc tế là cơ quan thúc đẩy và giám sát việc thực thi đó. Các tổ chức quốc tế như Quỹ tiền tệ quốc tế, Ngân hàng thế giới, đặc biệt là Liên Hợp quốc và các tổ chức khu vực như Tổ chức $A n$ ninh và Hợp tác châu Âu, Hiệp hội các nước Đông nam Á, Tổ chức các quốc gia châu Mỹ, Tổ chức châu Phi thống nhất,... đóng vai trò đáng kể trong quá trình này. Lấy ví dụ trong hệ thống Liên Hợp quốc, một trong những nhiệm vụ cơ bản của tổ chức này chính là góp phần xây dựng pháp luật quốc tế, đặc biệt là luật quốc tế về nhân quyền [7]. Liên Hợp quốc và các cơ quan chuyên môn của tổ chức này là cơ quan sáng lập ra ngành luật quốc tế về nhân quyền. Đây cũng là cơ quan trực tiếp tham gia soạn thảo, thông qua hàng trăm điều ước tuyên ngôn, tuyên bố và các văn kiện pháp lí liên quan, thành lập các cơ chế, thủ tục giám sát để tôn trọng, bảo vệ và thực thi quyền con người ở cấp độ toàn cầu. Các tổ chức quốc tế khác như Tồ chức Thương mại Thế giới đã thiết lập được hệ thống chuẩn mực và thẩm quyền giải quyết tranh chấp thương mại quốc tế nhằm điều chỉnh vấn đề lợi ích giữa các quốc gia cũng như các thiết chế phi nhà nước trong quan hệ thương mại quốc tế. Các thiết chế tài chính như Quỹ tiền tệ quốc tế hay Ngân hàng thế giới đều đã mở rộng phạm vi điều chỉnh của mình đến các lĩnh vực khác kể cả lĩnh vực nhân quyền hay trong xây dựng hợp tác với các quốc gia, đặc biệt là quốc gia đang phát triển [8]. Chính nhờ sự tham gia tích cực của tổ chức quốc tế mà phạm vi của luật quốc tế cũng dần được mở rộng hơn.

\section{Luật quốc tế và vai trò của các tổ chức phi chính phủ (NGOs)}

NGOs là một trong những chủ thể phi nhà nước có nhiều ảnh hưởng đến quá trình phát triển của pháp luật quốc tế trong thời gian vừa qua. Trong vài thập kỷ gần đây, NGOs đã có bước phát triển khá mạnh mẽ cả ở cấp độ quốc tế và cấp độ quốc gia. Các thiết chế này ngày càng tham gia nhiều hơn vào các diễn đàn pháp lí quốc tế. Steve Charnovitz cho rằng "nếu như không có các tổ chức phi chính phủ thì vai trò của pháp luật quốc tế sẽ kém phần quan trọng hơn trong quá trình phát triển của loài người" $[9$, tr.147]. Sự tham gia của NGOs trong hệ thống pháp luật quốc tế được thể hiện ở nhiều góc độ khác nhau bao gồm từ việc tham gia thúc đẩy sự thành lập hay tham gia vào các hội nghị quốc tế, tham gia xây dựng quy phạm, 
chuẩn mực pháp lí quốc tế, xây dựng điều ước mới hay thúc đẩy, giải thích, áp dụng và giám sát việc thực thi pháp luật [10]. Ngay từ khi mới ra đời, Liên Hợp quốc đã ghi nhận vai trò của NGOs trong các hoạt động của mình thông qua quy định tại Điều 71 của Hiến chương: "Hội đồng kinh tế và xã hội có thể thi hành mọi biện pháp để hỏi ý kiến những tổ chức phi chính phủ phụ trách những vấn đề thuộc thầm quyền của Hội đồng". Sự tham gia của NGOs như là một chủ thể tích cực của luật quốc tế được nghi nhận ở nhiều lĩnh vực khác nhau của ngành luật này. Chẳng hạn, trên lĩnh vực pháp luật quốc tế về nhân quyền, NGOs đã tham gia khá tích cực và trở thành một phần quan trọng của bộ máy nhân quyền Liên Hợp quốc. Nhiều tổ chức phi chính phủ còn được trao quy chế tư vấn và quan sát viên [11] của Liên Hợp quốc, nhờ đó đã được phép tham dự các hoạt động quốc tế về nhân quyền [12]. Hơn thế nữa, NGOs cũng có tác động đáng kể đến quá trình xây dựng và giải thích các chuẩn mực, điều ước nhân quyền cũng như giám sát quá trình thực thi các điều ước này cả ở cấp độ quốc tế và quốc gia. Trong thực tế, nhiều NGO đã có đóng góp trực tiếp vào quá trình soạn thảo nhiều văn kiện quốc tế về nhân quyền như là Công ước quốc tế về các quyền dân sự chính trị, Công ước quốc tế về các quyền kinh tế, xã hội và văn hóa; Công ước quốc tế về xóa bỏ mọi hình thức phân biệt đối xử với phụ nữ, Công ước quốc tế về quyền trẻ em [10]. Bản thân NGOs được phép cung cấp thông tin cho các ủy ban công ước về nhân quyền về tình hình thực hiện một điều ước cụ thể tại các quốc gia thông qua cơ chế báo cáo bóng (shadow report) hoặc được trực tiếp tham dự các phiên họp về nhân quyền cùng với quốc gia với tư cách là quan sát viên [13].

NGOs là một chủ thể tham gia vào hoạt động giải thích pháp luật. Chẳng hạn, năm 1984 NGOs đã tham gia xây dựng Nguyên tắc Siracusa - một nguyên tắc giúp làm rõ thêm nội dung và phạm vi của vấn đề tạm đình chỉ và hạn chế quyền được quy định trong Công ước quốc tế về các quyền dân sự, chính trị 1966 [14]. Thêm vào đó, NGOs đã tham gia tích cực vào quá trình vận động để thành lập các thiết chế quốc tế mới như Toà án Hình sự quốc tế. NGOs cũng tham dự các phiên xét xử tại Tòa án hình sự quốc tế, Tổ chức thương mại quốc tế hay tòa án khu vực về nhân quyền với tư cách là đại diện cho nạn nhân hay với tư cách là "bạn của tòa án" (Amici curiae). Chẳng hạn như, Tòa án nhân quyền châu Âu cho phép tổ chức phi chính phủ được gửi khiếu kiện và trở thành "bạn của tòa án" trong các vụ xét xử nhân quyền còn Tòa án nhân quyền châu Phi cũng cho phép tổ chức phi chính phủ được gửi khiếu kiện đối với các vi phạm về quyền con người $[15, \operatorname{tr} .147]$.

Với những hoạt động tích cực của mình, vị thế pháp lí của NGOs trong hệ thống pháp luật quốc tế được thể hiện ở cả hai cấp độ vừa là một pháp nhân, vừa là một chủ thể có năng lực tham gia vào trong quá trình phát triển của pháp luật quốc tế.

\section{Sự tham gia của cá nhân vào hệ thống pháp luật quốc tế}

Với sự phát triển của ngành luật quốc tế về nhân quyền, vai trò của cá nhân với tư cách là một chủ thể mới đã được ghi nhận. Nhiều học giả cho rằng bản thân cá nhân có quyền và trách nhiệm trực tiếp liên quan trong quá trình xây dựng và thực thi pháp luật nên đã có sự chuyển dịch về vai trò của cá nhân trong luật quốc tế từ chỗ chỉ coi là "đối tượng" sang là "chủ thể" của luật quốc tế [16]. Việc ghi nhận cá nhân như là những chủ thể mới của luật quốc tế được thể hiện rõ trong một số ngành luật như luật nhân quyền và luật hình sự quốc tế. Bằng chứng về sự tham gia cá nhân như là chủ thể của luật hình sự quốc tế có thể thấy trong phạm vi điều chỉnh của Tòa hình sự quốc tế về Nam Tư cũ, Tòa hình sự quốc tế về Rwanda và Tòa hình sự quốc tế [17]. Trên lĩnh vực nhân quyền, cá nhân là một chủ thể có thể tham gia vào cơ chế khiếu kiện cá nhân của một số cơ quan điều ước quốc tế và khu vực về nhân quyền. Chẳng hạn như, trên cơ sở một số điều kiện nhất định, cả sáu cơ quan điều ước nhân quyền của các công ước cơ bản đều có thẩm quyền xem xét khiếu nại và 
kháng thư của cá nhân [18]. Công ước Châu Âu về nhân quyền cho phép cá nhân là công dân của quốc gia thành viên công ước gửi khiếu kiện lên Tòa án Châu Âu về nhân quyền [19].

\section{Luật quốc tế và vai trò của các doanh nghiệp}

Một thiết chế phi nhà nước khác cũng được coi là chủ thể mới đang ngày càng có nhiều ảnh hưởng đến các mối quan hệ pháp lí quốc tế đó các doanh nghiệp, đặc biệt là tập đoàn xuyên quốc gia. Doanh nghiệp được ghi nhận là thiết chế quan trọng đóng vai trò không chỉ trên lĩnh vực kinh tế mà còn cả lĩnh vực chính trị, pháp lí quốc tế [20]. Stephen Tully cho rằng tập đoàn, doanh nghiệp có thể tham gia trực tiếp vào hình thành luật tập quán quốc tế, xây dựng các văn kiện luật mềm hay các điều ước quốc tế, tham gia giải quyết các tranh chấp quốc tế [21]. Chẳng hạn như, trên lĩnh vực luật biển, Công ước của Liên Hợp quốc về luật biển cho phép các nhà thầu và doanh nghiệp đệ trình tranh chấp lên Tòa án quốc tế [22]. Trên lĩnh vực luật môi trường quốc tế, chính các doanh nghiệp đã cùng tham gia xây dựng Công ước Liên Hợp quốc về biến đổi khí hậu cũng như các vòng đàm phán về Nghị định thư Kyoto [23, tr.169]. Các tập đoàn, doanh nghiệp cũng được coi là những chủ thể quan trọng trên lĩnh vực luật nhân quyền. Hiện nay, các chuẩn mực quốc tế về trách nhiệm nhân quyền của doanh nghiệp đã bước đầu được xây dựng theo hướng coi doanh nghiệp là một chủ thể tích cực.

Trong những năm gần đây, LHQ đã xây dựng, thông qua được một số văn kiện và cơ chế liên quan đến trách nhiệm quyền con người của doanh nghiệp như: Thỏa ước Toàn cầu (2000); Dự thảo Quy tắc về trách nhiệm của các Tập đoàn xuyên quốc gia và các doanh nghiệp khác đối với quyền con người (2003); Các Nguyên tắc hướng dẫn của Liên Hợp quốc về doanh nghiệp và quyền con người được Hội đồng Nhân quyền LHQ thông qua theo nghị quyết $17 / 4$ ngày 16/6/2011. Đặc biệt, hiện nay bản dự thảo công ước có tính ràng buộc pháp lí về quyền con người và trách nhiệm của doanh nghiệp đã được Nhóm công tác mở của Liên Hợp quốc soạn thảo [24]. Khi công ước này được thông qua, vai trò của doanh nghiệp như là một chủ thể chịu trách nhiệm tôn trọng quyền con người sẽ được chính thức ghi nhận.

\section{Kết luận}

Tựu trung lại, nhiều nghiên cứu gần đây cho thấy rằng, cho dù luật quốc tế là do quốc gia xây dựng nên, các thiết chế phi nhà nướcngày càng có sự tham gia nhiều hơn với tư cách là những chủ thể mới vào hệ thống pháp luật quốc tế. Bên cạnh nhà nước, các thiết chế phi nhà nước như tổ chức quốc tế, tổ chức phi chính phủ, cá nhân hay doanh nghiệp đã không còn giới hạn phạm vi hoạt động của mình trong lĩnh vực tư mà đã trở thành những chủ thể năng động, tích cực trong trật tự pháp lí quốc tế. Nói cách khác, luật quốc tế đang có sự tự chuyển đổi nhằm mở rộng phạm vi điều chỉnh sang các thiết chế tư nhân một cách trực tiếp hoặc gián tiếp. Tuy nhiên, cũng cần phải nhấn mạnh lại rằng cho dù các thiết chế phi nhà nước đang là những chủ thể mới và năng động, điều này không hề làm ảnh hưởng hay lu mờ vai trò của của chủ thể nhà nước. Bản thân thiết chế tư nhân hay phi nhà nước không thể thay thế được vai trò của nhà nước. Nhà nước vẫn tiếp tục là chủ thể chịu trách nhiệm chính trong toàn bộ quá trình soạn thảo, thông qua, kí kết, phê chuẩn và thực thi luật quốc tế.

Cho đến nay, sự ghi nhận vai trò của các chủ thể tư nhân vẫn chưa đủ để xác định nghĩa vụ pháp lí mạnh mẽ và hiệu quả cho các thiết chế này. Trách nhiệm và quyền lực của các chủ thể phi nhà nước cần được tiếp tục pháp điển hóa. Chẳng hạn, hiện nay sự tham gia của cá nhân vào pháp luật quốc tế chủ yếu chỉ với tư cách là đối tượng nhiều hơn là chủ thể $[25$, tr.148]. Đối với các tổ chức phi chính phủ, mặc dù mức độ ảnh hưởng khá rộng rãi nhưng vị trí pháp lí của các tổ chức này cũng chưa thực sự rõ ràng. Hiện vẫn chưa có quy định pháp lí quốc tế nào về tư cách pháp nhân của 
NGO và cũng chưa có một khuôn khổ pháp lí hiệu quả nào quy định cụ thể về cách thức hợp tác giữa tổ chức phi chính phủ và các thiết chế pháp lí quốc tế khác. Đối với doanh nghiệp thì mức độ ảnh hướng đối với các lĩnh vực pháp luật quốc tế cũng còn nhiều hạn chế. Mặc dù doanh nghiệp có quyền lực kinh tế rất lớn nhưng chủ thể này chưa được trực tiếp tham gia vào quá trình soạn thảo hay bỏ phiếu thông qua điều ước quốc tế. Có thể nói, liên quan đến vai trò của các tập đoàn, doanh nghiệp đối với một số ngành của luật như luật quốc tế về nhân quyền, thì chủ thể này vẫn còn hoạt động trong môi trường chân không về mặt pháp lí vì rằng, luật nhân quyền vẫn chưa đưa ra được các quy định có tính ràng buộc trực tiếp về trách nhiệm pháp lí cho doanh nghiệp. Do vậy, việc ghi nhận vai trò của các chủ thể phi nhà nước trong pháp luật quốc tế vẫn đang trong quá trình được tiếp tục xây dựng và hoàn thiện.

\section{Tài liệu tham khảo}

[1] Alina Kaczorowska, Luật công pháp quốc tế (Public International Law ) (NXB Routledge, 2010).

[2] Milena Sterio, Sự phát triển của pháp luật quốc tế (The Evolution of International Law) (2008) Mạng lưới nghiên cứu khoa học xã hội (Social Science Research Network).

[3] Quy chế của Tòa án công lý quốc tế, điều 38 (1).

[4] Alina Kaczorowska, Luật Công pháp quốc tế (Public International Law) (NXB Routledge).

[5] Alina Kaczorowska, Luật công pháp Quốc tế (Public International Law) ( NXB Routledge, 2010).

[6] Henderson, C, Tìm hiều về luật quốc tế (Understanding international law), NXB WileyBlackwell, 2010.

[7] Liên Hợp quốc đã thông qua hơn 550 điều ướcvề nhiều lĩnh vực khác nhau như nhân quyền, tị nạn, môi trường, luật biển... Xem: Vai trò của Liên Hợp quốc trong pháp luật quốc tế (Role of the United Nations in International Law). Bài viết có tại địa chì: $<$ http://treaties.un.org/doc/source/events/2011/Press ki t/fact_sheet5_english.pdf $>$ ( truy cập ngày 4/9/2017).

[8] Gernot Brodnig, Ngân hàng thế giới và nhân quyền: nhiệm vụ bất khả thi? (The World Bankand Human Rights: Mission Impossible?) (2005) <
http://www.hks.harvard.edu/cchrp/Web\%20Working\% 20Papers/BrodnigHR\&WorldBank.pdf $>$.

[9] Steve Charnovitz, Tổ chức phi chính phủ và luật quốc tế (Non-Govermental Organizations and International Law) trong sách của in Andrea Bianchi (chủ biên), Thiết chế phi nhà nước và luật quốc tế (Non-State Actors and International Law) (NXB Ashgate, 2009).

[10] Xem: Cenap Çakmak, Xã hội dân sự trong luật quốc tế và Chính trị thế giới: Định nghĩa, khung khái niệm và vấn đề (Civil Society Actors in the International Law and World Politics: Definition, Conceptual Framework, Problems ) (2007). Tài liệu có tại địa chỉ: $<$ http://www.humansecuritygateway.com/documents/ GPF IJCSL civilsocietyactorsinternationallaw.pdf> , (truy cập ngày 4/9/2014).

[11] Hội đồng Kinh tế và Xã họi đã thông qua một số nghị quyết như Nghị quyết 1996/31 về mối quan hệ tư vấn giữa Liên Hợp quốc và tổ chức phi chính phủ.

[12] Ví dụ, tại Hội nghị quốc tế về nhân quyền lần thứ hai tại Viên năm 1993, hơn 1500 tổ chức phi chính phủ đã tham dự.

[13] Liên Hợp quốc, Nghị quyết 1996/31 về mối quan hệ tư vấn giữa Liên Hợp quốc và các tổ chức phi chính phủ (Resolution 1996/31 on Consultative relationship between the United Nations and nongovernmental organizations) (1996); Hội đồng nhân quyền Liên Hợp quốc, Sự tham gia của tổ chức phi chính phủ vào Hội đồng nhân quyền (NGO Participation in the Human Rights Council). Tài liệu có tại địa chỉ:

$<$ http://www.ohchr.org/EN/HRBodies/HRC/Pages/ NgoParticipation.aspx $>$ (truy cập ngày 4/9/2014).

[14] Steve Charnovitz, Tổ chức phi chính phủ và luật quốc tế (Nongovernmental Organizations and International Law),Tạp chí luật quốc của Mỹ (American Journal of International law) số 348 (2006).

[15] Steve Charnovitz,Tổ chức phi chính phủ và luật quốc tế (Non-Govermental Organizations and International Law) trong sách của in Andrea Bianchi (Chủ biên), Thiết chế phi nhà nước và luật quốc tế (Non-State Actors and International Law) (NXB Ashgate, 2009).

[16] Robert McCorqodale, Cá nhân và hệ thống pháp lý quốc tế ( The Individual and the International Legal System) trong sách của Andrea Bianchi (chủ biên), Thiết chế phi nhà nước và luật quốc tế (Non-State Actors and International Law ) (NXB Ashgate, 2009).

[17] Nguyên tắc về trách nhiệm hình sự của cá nhân được quy định tại điều 7 (1) của Quy chế về Tòa hình sự về Nam Tư cũ, điều 6(1) của Quy chế về Tòa hình sự Rwandavà Quy chế Rome về thành lập Tòa án hình sự quốc tế. 
[18] Liên Hợp quốc, Thủ tục khiếu kiện của các cơ quan nhân quyền (Human Rights Bodies - Complaints Procedures). Tài liệu có tại địa chỉ: $<$ http://www2.ohchr.org/english/bodies/petitions/ind ex.htm\#communcications>, (truy cập ngày 3/9/2014).

[19] Công ước châu Âu về Nhân quyền.

[20] Stephen Tully, Doanh nghiệp và việc xây dựng pháp luật quốc tế (Corporations and International Law Making) (NXB Maritinus Nijhoff, 2007).

[21] Stephen Tully, nt.

[22] Xem Công ước Liên Hợp quốc về luật biển 1982.
[23] Stephen Tully, nt tr.169.

[24] Xem, Dự thảo số 0 về văn kiện ràng buộc pháp lý trong luật quốc tế về quyền con người về hoạt động của tập đoàn xuyên quốc gia và các doanh nghiêp khác. Tài liệu có tại địa chỉ https://www.ohchr.org/Documents/HRBodies/HRCo uncil/WGTransCorp/Session3/DraftLBI.pdf (Truy cập ngày 9/9/2018).

[25] Alice De Jonge, Tập đoàn xuyên quốc gia và Luật quốc tế (Transnational Corporations and International Law) ( NXB Edward Elgar, 2011).

\title{
International Law and the Role of Non-State Actors
}

\author{
Nguyen Thi Thanh Hai \\ Institute of Human Rights, Ho Chi Minh National Political Academy \\ 135 Nguyen Phong Sac, Cau Giay, Hanoi, Vietnam
}

\begin{abstract}
This article explores the development process of the International law and changes in its scope and subject over the recent decades as a result of the changes in international economical, political and legal orders. By analysing the role of non-state actors such as international organizations, NGOs, corporations and individuals, this article argues that states, though remaining important, are no longer the only subject. The article shows that the International law is also regulated by non-state actors.
\end{abstract}

Keywords: International law, subject, non-state actor. 